\title{
Design of Multi-Stage Roll Die Forming Process for Drum Clutch with Artificial Neural Network
}

\author{
Jae-Hong Kim ${ }^{1}$, Jae-Chang Ryu ${ }^{2}$, Woo-Sik Jang ${ }^{2}$, Joon-Hong Park ${ }^{3}$, Young-Hoon Moon ${ }^{1}$ (D) and \\ Dae-Cheol Ko ${ }^{2, *(\mathbb{D})}$
}

1 Engineering Research Center of Innovative Technology on Advanced Forming, Pusan National University, 2, Busandaehak-ro 63beon-gil, Geumjeong-gu, Busan 46241, Korea; kjh86@pusan.ac.kr (J.-H.K.); yhmoon@pusan.ac.kr (Y.-H.M.)

2 Department of Nanomechatronics Engineering, Pusan National University, 2, Busandaehak-ro 63beon-gil, Geumjeong-gu, Busan 46241, Korea; jcr0416@pusan.ac.kr (J.-C.R.); petitpe86@naver.com (W.-S.J.)

3 Department of Mechanical Engineering, Dong-A University, 37, Nakdong-daero 550beon-gil, Saha-gu, Busan 49315, Korea; acttom@dau.ac.kr

* Correspondence: dcko@pusan.ac.kr; Tel.: +82-51-510-3697

Citation: Kim, J.-H.; Ryu, J.-C.; Jang, W.-S.; Park, J.-H.; Moon, Y.-H.; Ko, D.-C. Design of Multi-Stage Roll Die Forming Process for Drum Clutch with Artificial Neural Network. Materials 2021, 14, 69. https:// dx.doi.org/10.3390/ma14010069

Received: 24 November 2020 Accepted: 24 December 2020 Published: 25 December 2020

Publisher's Note: MDPI stays neutral with regard to jurisdictional claims in published maps and institutional affiliations.

Copyright: $\odot 2020$ by the authors. Licensee MDPI, Basel, Switzerland. This article is an open access article distributed under the terms and conditions of the Creative Commons Attribution (CC BY) license (https:/ / creativecommons.org/ licenses/by/4.0/).

\begin{abstract}
The multi-stage roll die forming (RDF) process is a plastic forming process that can manufacture a transmission part with a complex shape, such as a drum clutch, by using a die set with rotational rolls. However, it is difficult to satisfy dimensional accuracy because of spring-back and unfilling. The purpose of this study is to design a multi-stage RDF process for the manufacturing of a drum clutch to improve dimensional accuracy using an artificial neural network (ANN). Finite element (FE) simulation of the multi-stage RDF process is performed to predict the dimensional accuracy according to various clearances for each stage. Moreover, the ANN is used to determine the relationship between the clearance and dimensional accuracy of the drum clutch to reduce the number of FE simulation. The results of the FE simulation and ANN are used to determine the optimal clearance for each stage of the RDF process. Finally, the drum clutch is fabricated using the determined conditions. The experimental results are in good agreement with the results of FE simulation from the aspect of outer diameter, inner diameter, thickness of outer tooth, thickness of inner tooth, and face thickness of tooth.
\end{abstract}

Keywords: multi-stage roll die forming; drum clutch; dimensional accuracy; artificial neural network

\section{Introduction}

Recently, power loss reduction and the application of lightweight components have been increasing fuel efficiency in the automotive industry to comply with strict environmental regulations [1,2]. Especially, the multi-stage automotive transmission system has been investigated in order to improve fuel efficiency. The multi-stage automotive transmission system includes many components, such as clutches, brakes, and gears. A drum clutch, which is the main component in automotive transmission systems, must satisfy minimum requirements concerning both strength and dimensional accuracy.

The components used in automotive transmission systems are generally manufactured by machining process or various cold forming processes, such as deep drawing, forging, groove threading, upsetting, and ironing [3-7]. The machining process leads to a decrease in tooth strength of components because a grain flow is cut by a shaving and hobbing process [3]. In the case of the cold forming process, the life of tools can be shortened by large forming load and productivity is low owing to complex manufacturing procedure $[8,9]$. Therefore, the application of effective manufacturing processes is required to prevent decrease in tooth strength and improve the productivity of the drum clutch.

The multi-stage roll die forming (RDF) has been introduced to manufacture a drum clutch, of which a tooth is formed by a successive drawing process using a die set with 
rotational rolls. The multi-stage RDF process can prevent a reduction in the tooth strength of the drum clutch caused by the cut of grain flow and improve productivity via the drawing process. The rotational rolls can decrease forming load and frictional force between blank and tools. Another advantage of the multi-stage RDF process is that conventional equipment for press forming equipment can be used instead of special equipment [10].

However, multi-stage RDF process still has some problems, such as spring-back, unfilling, and elevated tool temperature during continuous manufacturing process, which mean that ensuring the dimensional accuracy of the drum clutch is difficult [10-13]. The dimensional accuracy of the final product depends on the design parameters of each process, such as the thickness of the blank, diameter of the roll, and clearance between the roll and mandrel [14-16]. In addition, dimensional errors can occur in subsequent stages of the multi-stage RDF process because of the elevated temperature of the tool. Therefore, an effective design method is required to achieve the dimensional accuracy of the product according to process parameters.

The purpose of this study is to design a multi-stage RDF process for the manufacturing of a drum clutch that improves dimensional accuracy using an artificial neural network (ANN). Finite element (FE) simulation of the multi-stage RDF process was performed to predict the dimensional accuracy according to various clearances for each stage. Moreover, the ANN is used to infer the relationship between the clearance and the dimensional accuracy of the drum clutch to reduce the number of FE simulations. Finally, the drum clutch was fabricated using conditions determined by the FE simulation and ANN, and the dimensional accuracy of manufactured drum clutch was compared with the results of FE simulation.

\section{Multi-Stage Roll Die Forming Process for Drum Clutch}

\subsection{Drum Clutch}

The drum clutch, which is a main component in automotive transmission systems, performs an important role in power transmission and is the cause of much of the vibration and noise produced by an automobile. Improving the power transmission and reducing both the vibration and noise requires excellent dimensional accuracy, for example, in terms of tooth thickness, the unfilling at corners, and diameters of the drum clutch. Figure 1 shows the main dimensions and the tolerance of the drum clutch, which has two peripheral walls with different diameters.

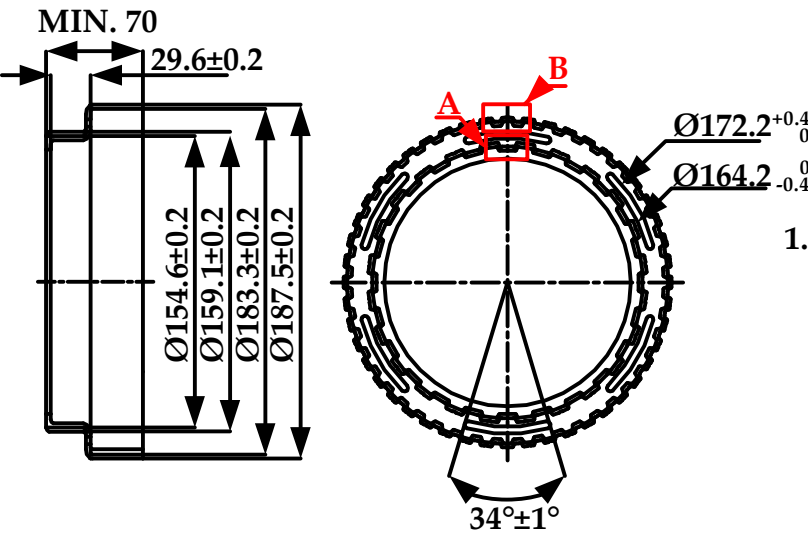

Main dimension
Unit : $\mathrm{mm}$
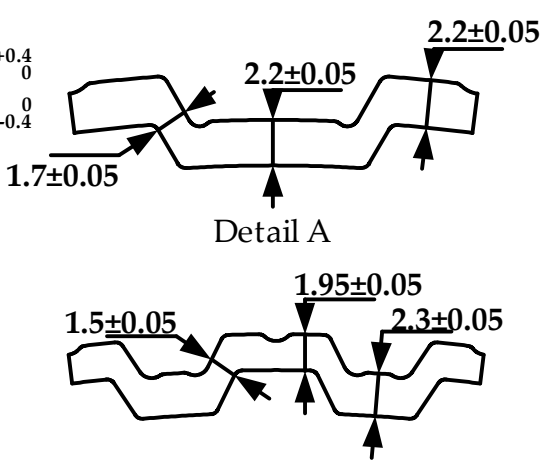

Detail B

Figure 1. Dimensions of drum clutch.

\subsection{Application of Multi-Stage Roll Die Forming Process}

Figure 2 shows a schematic drawing of the 1st and 2nd stages of the RDF process. The inner and outer teeth of the drum clutch are formed by rolls installed within the die set during the downward movement of the mandrel and pad, similar to the case of deep drawing. The roll is rotated by the frictional force between the blank and the roll. 


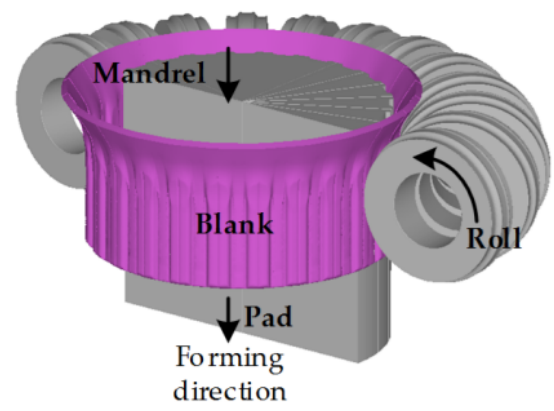

(a)

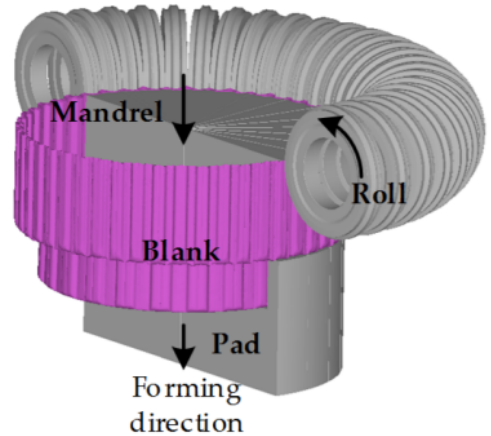

(b)

Figure 2. The schematic drawing multi-stage roll die forming (RDF) process, (a) 1st stage of RDF and (b) 2nd stage of RDF.

In this study, the multi-stage RDF process for manufacturing the drum clutch consists of two stages. The 1st stage of this process consists of three steps of RDF process to form small peripheral wall whose diameter is $154.6 \mathrm{~mm}$. An initial blank is formed into the cup shape with rough tooth in the 1st step. The precise tooth shape is formed by the 2 nd step, and the 3rd step is sizing process to manufacture the final product with improved dimensional accuracy. The 2nd stage of this process is to form large peripheral wall, of which diameter is $183.3 \mathrm{~mm}$, and proceed subsequently by same procedure with 1st stage RDF process. Figure 3 shows the shapes of the roll and mandrel for a multi-stage RDF process for each stage.
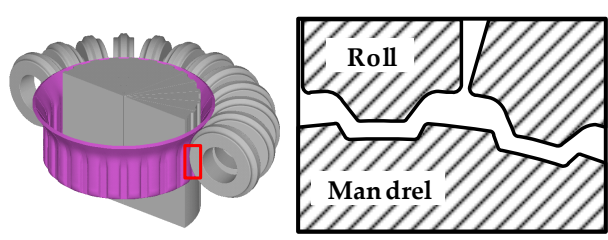

1st step of 1 st RDF
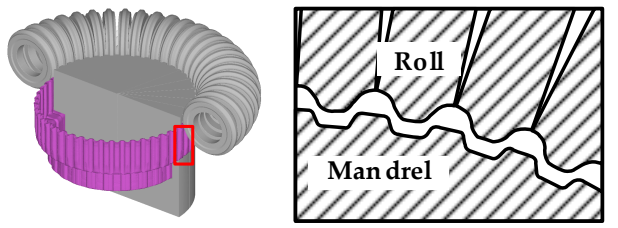

1st step of 2nd RDF

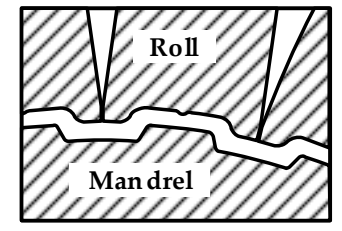

2nd step of 1 st RDF

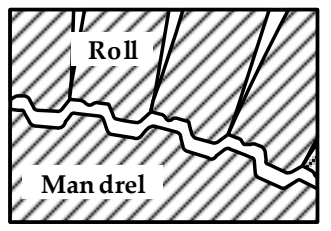

2nd step of 2 nd RDF

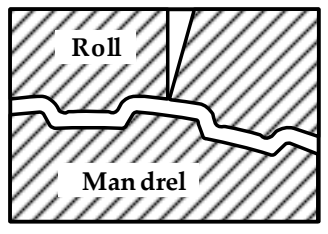

3rd step of 1 st RDF

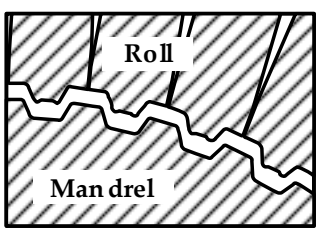

3rd step of $2 \mathrm{nd} \mathrm{RDF}$

Figure 3. Tool shapes of the multi-stage RDF process.

\section{FE Simulation of Multi-Stage Roll Die Forming Process}

\subsection{Construction of FE Model}

The material used in this study was SAPH440 with a thickness of $3.6 \mathrm{~mm}$. Uniaxial tensile test was performed using material test system equipment (MTS Landmark ${ }^{\mathrm{TM}} 100 \mathrm{kN}$, MTS Systems Corporation, Eden Prairie, MN, USA) to obtain mechanical properties for application of FE simulation. Tests of SAPH440 were carried out according to ASTM E8M [17], and results are summarized in Table 1. The material model used in this study was the Hollomon equation, which is the relationship between the representative stress and strain. 
Table 1. Mechanical properties for SAPH440.

\begin{tabular}{cc}
\hline Mechanical Properties & Values \\
\hline Yield strength & $315 \mathrm{MPa}$ \\
Tensile strength & $436 \mathrm{MPa}$ \\
Strength coefficient (K) & $722.2 \mathrm{MPa}$ \\
Strain hardening exponent (n) & 0.198 \\
Material model (Hollomon equation) & $\sigma=722.2 \cdot \varepsilon^{0.198}$ \\
\hline
\end{tabular}

In this study, the FE simulation was performed using DEFORM 3D (Version 11, Scientific Forming Technologies Corporation, Columbus, OH, USA), with a 1/24 section of blank and dies considering the symmetry of the drum clutch. The blank was meshed with approximately 450,000 hexahedral elements, and a symmetric boundary condition at the radial edge of the blank was imposed on the FE model. Figure 4 shows the FE model for the 1st and 2nd stages of the RDF process, and the conditions for the FE simulation are listed in Table 2. The roll was rotated by the friction between the blank and the roll. In the case of RDF, the frictional force at the interface between the blank and the roll is very low because of the rolling contact of the blank with the rotational roll. In addition, actual RFD process is performed with sufficient and continuous lubrication for the roll and blank. Thus, the friction factor $(\mathrm{m})$ in the RDF is assumed to be 0.02 between the roll and blank [15]. The effect of anisotropy is ignored owing to a relatively small drawing depth of $60 \mathrm{~mm}$ and a small plane strain during the RDF, compared with general sheet metal forming. Additionally, SAPH440 has almost isotropic properties because this blank is hot rolled steel plate with large thickness of $3.6 \mathrm{~mm}$ [18].

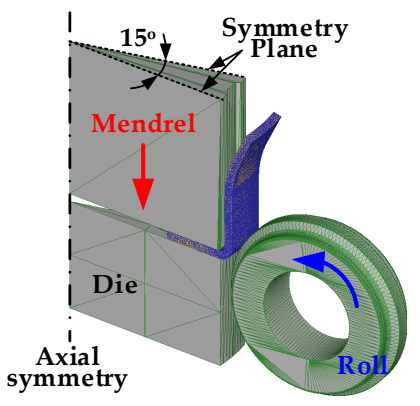

1st step of 1st RDF

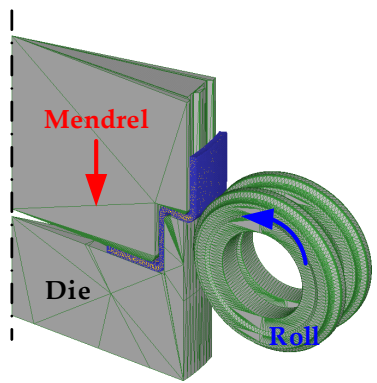

1st step of 2 nd RDF

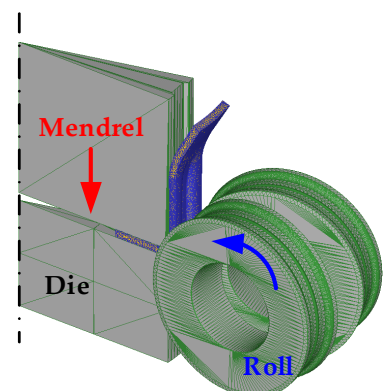

2nd step of 1st RDF

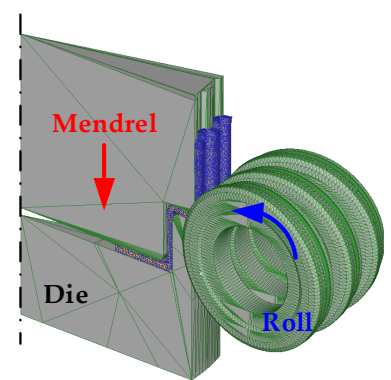

2nd step of 2nd RDF

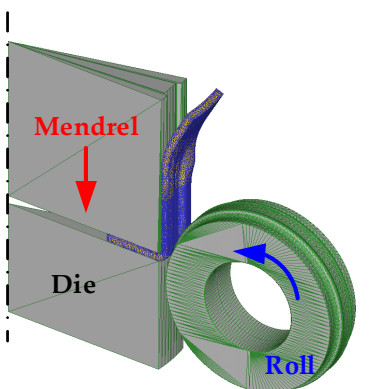

3rd step of 1st RDF

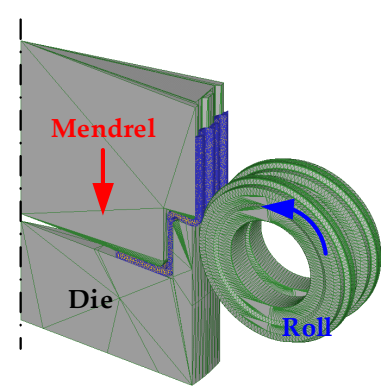

3rd step of 2nd RDF

Figure 4. FE model for RDF process. 
Table 2. The conditions for the finite element (FE) simulation.

\begin{tabular}{ccc}
\hline \multicolumn{2}{c}{ Process Condition } & Values \\
\hline \multicolumn{2}{c}{ Material } & SAPH440 \\
\hline \multicolumn{2}{c}{ Punch(mandrel) speed } & $500[\mathrm{~mm} / \mathrm{s}]$ \\
\hline \multirow{2}{*}{ Friction factor $(\mathrm{m})$} & Blank with die and mandrel & 0.12 \\
& Blank with roll & 0.02 \\
\hline
\end{tabular}

\subsection{Results of the FE Simulation}

The clearance between the mandrel and the roll during the RDF for the drum clutch is the main process parameter affecting the dimensional accuracy of the final product. In this study, the clearances are defined as design parameters, which are summarized in Table 3.

Table 3. Cases of FE simulation.

\begin{tabular}{cccccc}
\hline Case & $\begin{array}{c}\text { Clearance of } \\
\text { 1st Stage [\%t] }\end{array}$ & $\begin{array}{c}\text { Clearance of } \\
\text { 2nd Stage [\%t] }\end{array}$ & Case & $\begin{array}{c}\text { Clearance of } \\
\text { 1st Stage [\%t] }\end{array}$ & $\begin{array}{c}\text { Clearance of } \\
\text { 2nd Stage [\%t] }\end{array}$ \\
\hline 1 & 0 & 0 & 2 & 0 & 5 \\
3 & 0 & 10 & 4 & 5 & 0 \\
5 & 5 & 5 & 6 & 5 & 10 \\
7 & 10 & 0 & 8 & 10 & 5 \\
9 & 10 & 10 & & & \\
\hline
\end{tabular}

Figure 5 shows the results of the FE simulation of the dimensional accuracy with various clearances. The predicted unfilled or overfilled area ranged from $0.1419 \mathrm{~mm}^{2}$ to $0.2384 \mathrm{~mm}^{2}$ for each tooth. In the case of zero clearance, an unfilling phenomenon occurred, whereas an over-filling phenomenon was observed in the case of $10 \%$ t clearance. Figure 6 shows the deformed shape and distribution of the effective strain for case 5 . The effective strain largely increases during the 1st and the 2nd step of each stage because the inner and outer teeth are almost deformed in these steps. In the 3rd step, which is used for a sizing process, the effective strain is similar to the 2 nd step because amount of deformation is small. A large distribution of the effective strain is also observed for the inner teeth owing to a relatively small clearance and large deformation. This may result in an increase in the level of wear on the punch and roll dies during mass production [15].

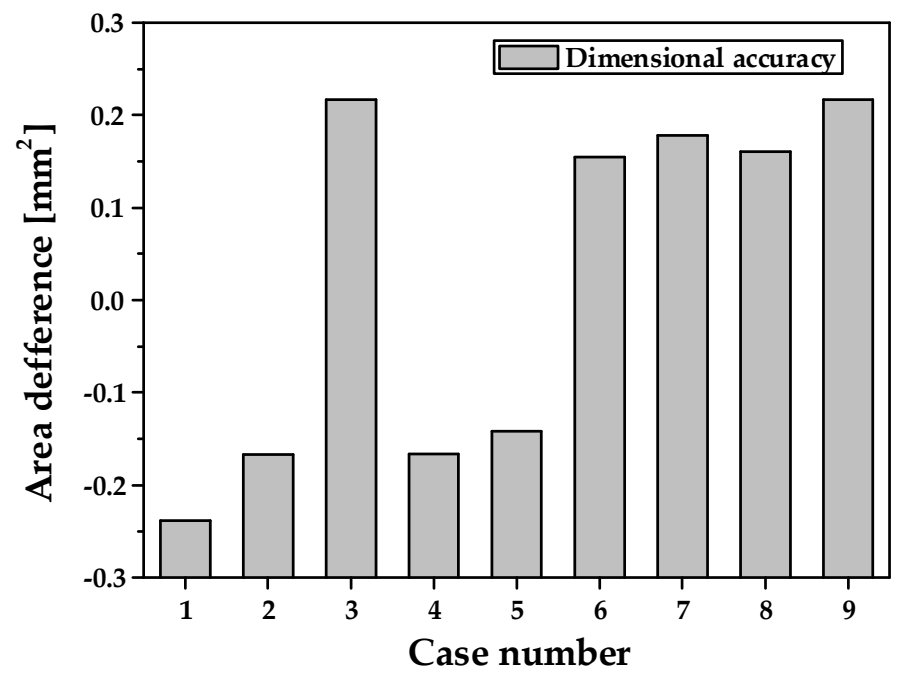

Figure 5. Results of the FE simulation for dimensional accuracy. 


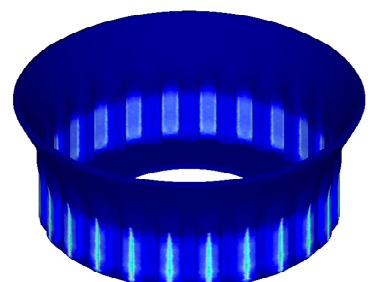

1st step of 1st RDF

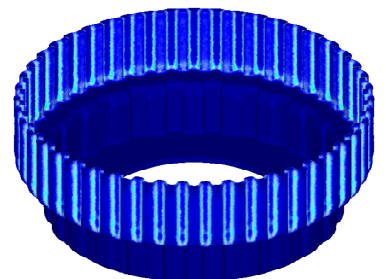

1 st step of 2 nd RDF

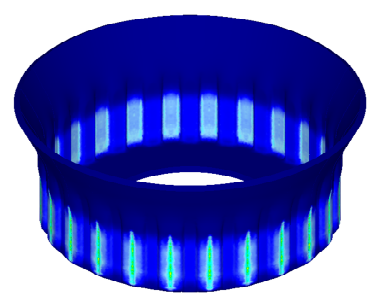

2nd step of 1 st RDF

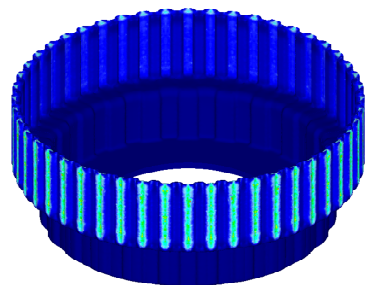

2nd step of 2 nd RDF

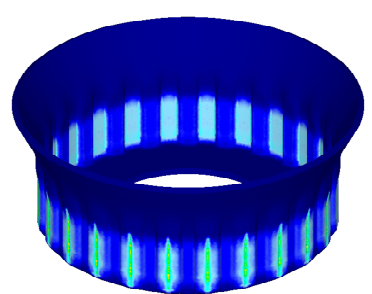

3 rd step of 1 st RDF

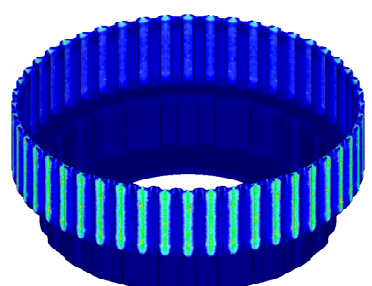

3rd step of 2 nd RDF

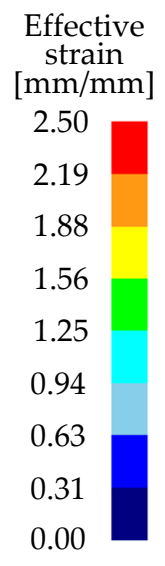

Figure 6. Results of the FE simulation of the deformed shape and distribution of the effective strain.

\section{Optimization of Multi-Stage Roll Die Forming Process \\ 4.1. Artificial Neural Network}

ANN is a computational model inspired by natural neurons that is applied to solve complex functions in various fields, including pattern matching, data compression, and functional approximation [19]. Multilayer perceptron trained by back propagation is the most popular and useful method used by ANNs; it consists of a number of neurons, a single hidden layer, and a nonlinear activation function. In this study, the ANN was employed to predict the dimensional accuracy of a drum clutch with a sigmoid transfer function, and it was trained to learn the nonlinear relationship between the process parameters and the dimensions of the deformed part. The back propagation algorithm was adopted to train the networks, where the dimensions predicted by FE simulation was used as the training dataset.

\subsection{Optimization of Clearance with Artificial Neural Network}

As mentioned above, the results of the FE simulation were used to train and develop the ANN. In this study, the predicted sectional area of the teeth is taken as the training input data according to clearances of each RDF stages. The output data is trained with back-propagation algorithm by ANN. In the learning process, the network is presented with an input pattern and a corresponding desired output pattern. Using the weights and thresholds, the network produces the output pattern, which is compared with the desired output pattern [20]. The results of ANN were utilized to determine the process window as shown in Figure 7. The process window is used to obtain the relationship between process parameters and dimensional accuracy and could predict dimensional accuracy for all combinations within a whole range of process parameters. In order to ensure process window, the predicted sectional area of tooth by ANN was compared with the prediction results by FE simulation. The sectional area was precisely predicted by process window in comparison with result of FE simulation within maximum error of $0.7 \%$. Finally, the optimized clearances were determined to be $6 \% \mathrm{t}$ for the 1st stage and $5 \% \mathrm{t}$ for the 2nd stage for the multi-stage RDF process. 


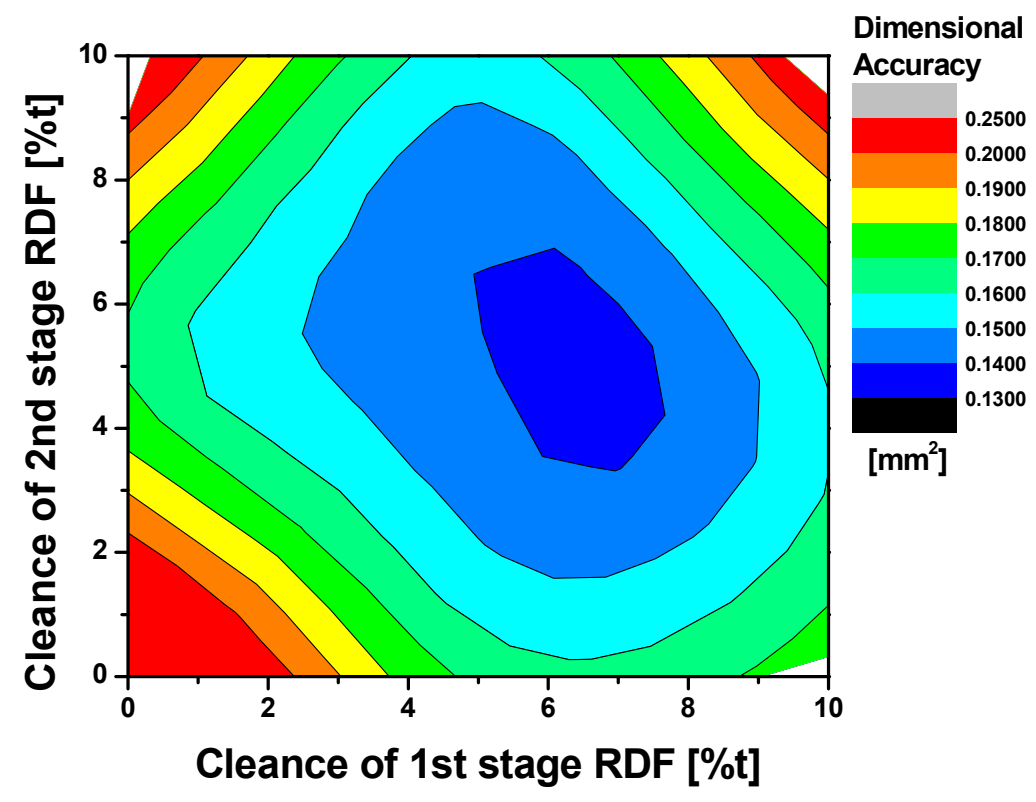

Figure 7. Process window to predict dimensional accuracy.

\subsection{FE Simulation of the Manufacturing Process of the Drum Clutch with Optimized Clearance}

Most manufacturing processes of gear components are designed for the initial products. However, the actual manufacturing process is continuous and repetitive. In addition, the die temperature is increased due to friction between the product and the die. Therefore, it is necessary to predict the temperature limit of the die to maximize the dimensional accuracy of the drum clutch.

An FE simulation of five cycles from the initial product to the fifth product was performed to obtain the temperature increase and distribution as shown in Figure 8. Die modeling was performed to investigate the dimensional accuracy at the maximum temperature, which was assumed to be $200{ }^{\circ} \mathrm{C}$ considering the maximum temperature of the fifth product. The predicted thickness for final product of each stage was within allowable tolerance of $\pm 0.05 \mathrm{~mm}$, as shown in Figure 9. The mechanical properties of metals were also affected by elevated temperatures. In particular, the yield strength and tensile strength decreased at elevated temperatures. Therefore, structural simulation of the die at elevated temperatures was required to predict the safety of the die.

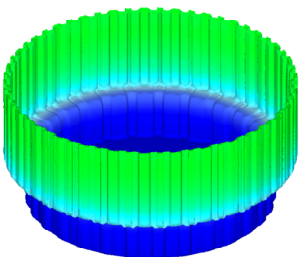

1st product

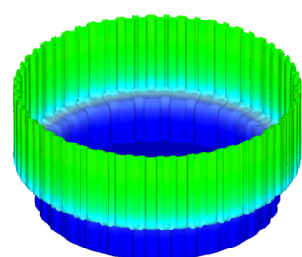

2nd product

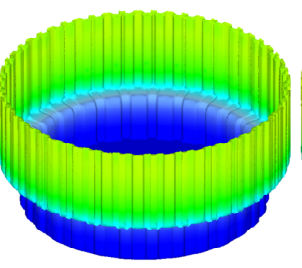

3rd product

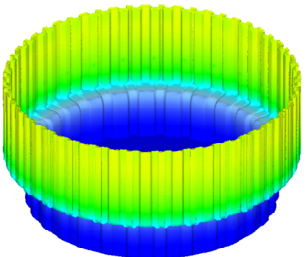

4th product

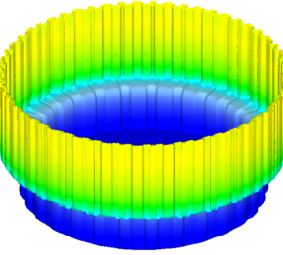

5th product
Temp.

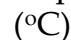

200

150

100

50

0

Figure 8. Temperature distributions from the 1 st product to the 5 th product. 


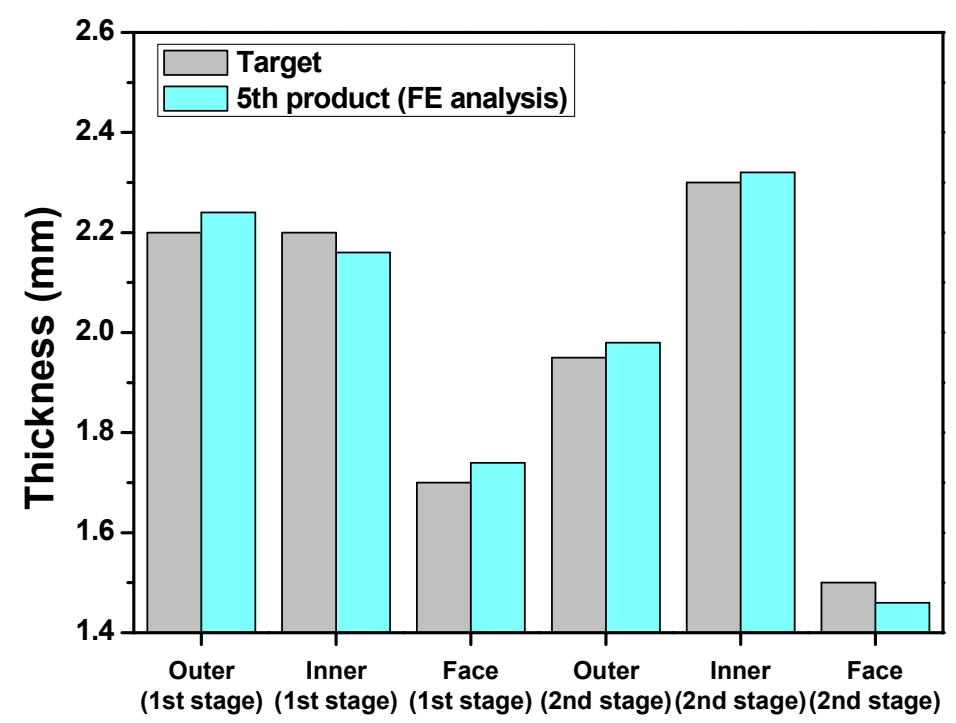

Figure 9. The predicted thickness for the 5 th product.

Structural simulation was performed for the 1st and 2nd stages of RDF processes because the maximum stress applied to the die was measured during the sizing process. Figure 10 shows the results of heat transfer and forming simulation, which were used to perform the structural simulation for the rolls. The temperature distribution and the maximum load from the FE simulation of the die with a maximum temperature of $200{ }^{\circ} \mathrm{C}$ were applied to the roll. The material used for the die was AISI D2. Figure 11 shows the results of the structural simulation. The maximum stresses of 1 st and 2 nd stages of RDF processes are $1100 \mathrm{MPa}$ and $1550 \mathrm{MPa}$, respectively. In addition, the compressive yield strength of the material is $1900 \mathrm{MPa}$ [21,22]. Consequently, the plastic deformation of dies may not have occurred because the stresses on the die during both the 1st and 2nd stages were lower than their compressive yield strength. The fatigue failure could have occurred on the roll during the mass production because the maximum stress was relatively large compared with yield strength. The fatigue life of tool could be improved by prevention of stress concentration during RDF process due to rotational roll.

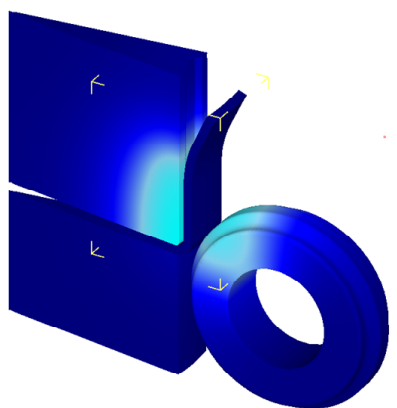

Initial state of 1st stage

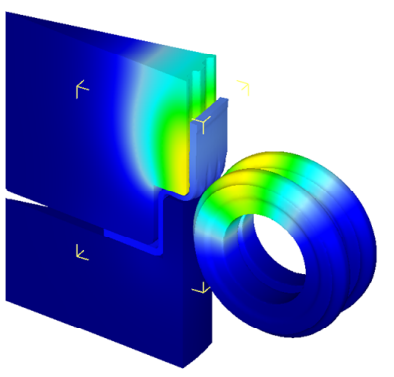

Initial state for 2nd stage

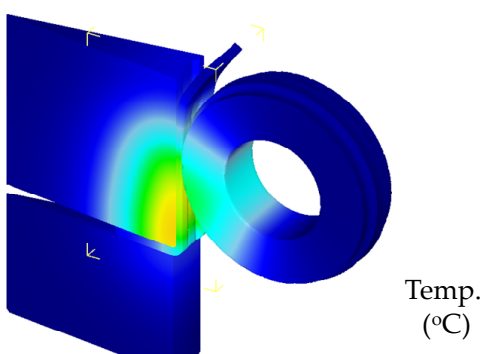

$\left({ }^{\circ} \mathrm{C}\right)$
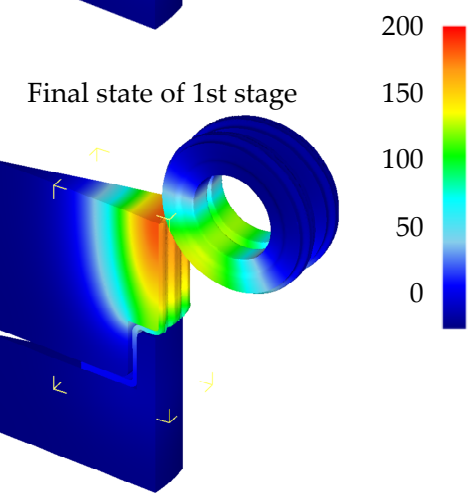

Final state for 2nd stage

Figure 10. The results of heat transfer and forming simulation for 5th product. 


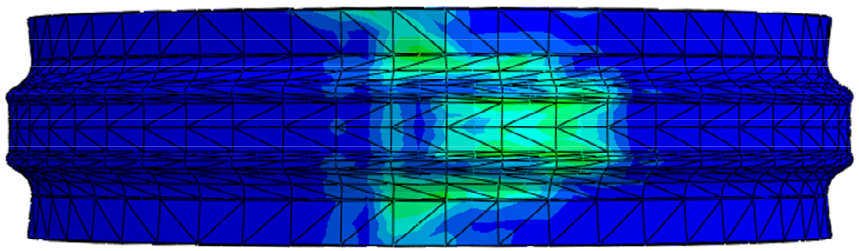

\section{S,Mises}

(Avg: 75\%)

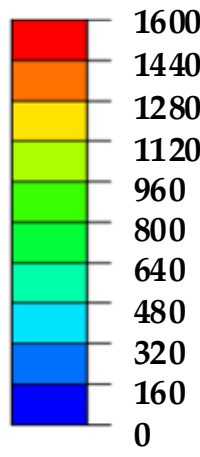

Figure 11. Result of structural simulation of the rolls of the 2nd RDF process.

\section{Experimental Verification}

The experiments for multi-stage RDF process to manufacture the drum clutch were performed to verify suggested design method based on the results of FE simulation and ANN. Figure 12 shows the shapes of the mandrel and roll dies for the 2nd step of each stage. The roll and the housing were surrounded by a case to prevent the generation of gap between the housing during the multi-stage RDF process. In the RDF die set, 48 rolls were installed and tools were manufactured with AISI D2. The experiments were also performed with same conditions for FE simulations.
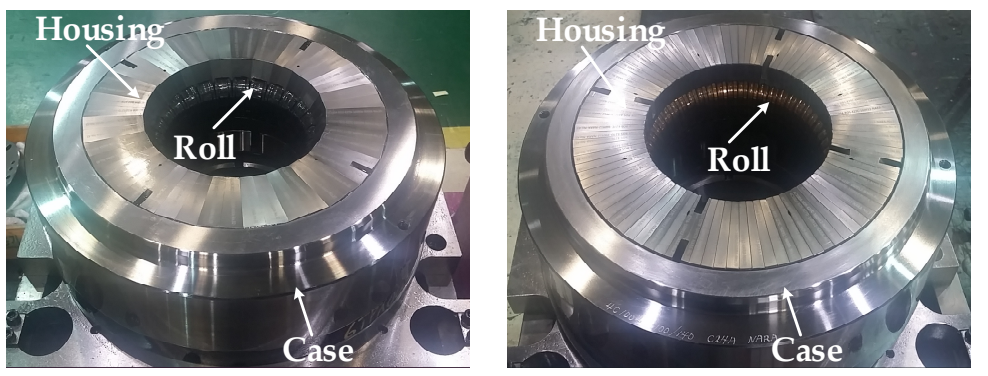

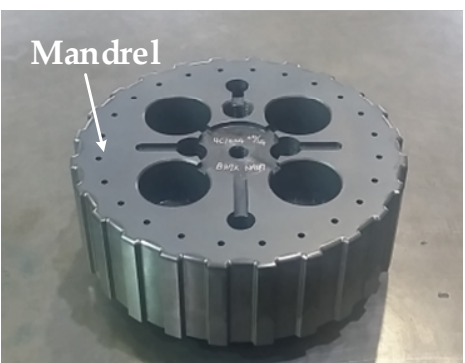

1st stage of RDF die set

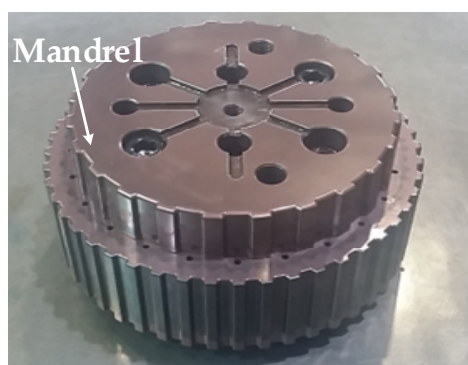

2nd stage of RDF die set

Figure 12. Die set for manufacturing the drum clutch.

Figure 13 shows the results of the experiment and the FE simulation for multi-stage RDF process. The experimental results show that the tooth shape is quite sound, and excellent dimensional accuracy of product is achieved by suggested optimal clearance. Additionally, the results of the FE simulation are in good agreement with the experimentally measured dimensional accuracies within a maximum error of $2.09 \%$ as summarized in Table 4 . These results showed that deformation behavior in actual process could be described well by FE simulation of multi-stage RDF process used in this study. The dimensional accuracy of the final product satisfies the target dimension within an allowable tolerance. Therefore, the experimental results demonstrate the validity of the optimal design parame- 
ters determined in this study. The process window based on FE simulation and ANN can be used efficiently for determination of process parameters in multi-stage RDF process to manufacture drum clutch.

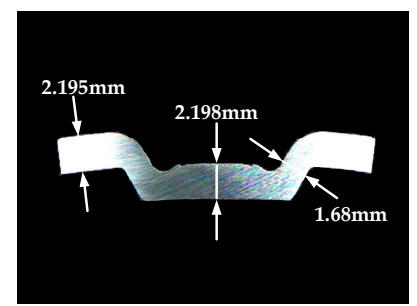

Experiment of 1st stage RDF process

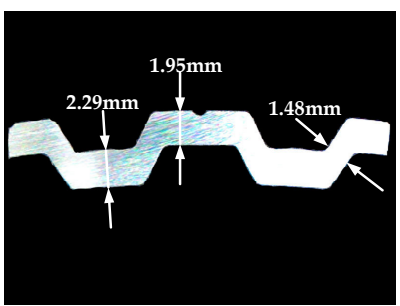

Experiment of 2nd stage RDF process

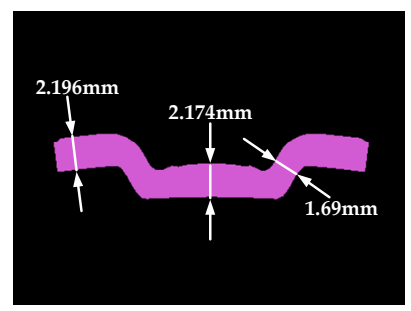

FE analysis of 1st stage RDF process

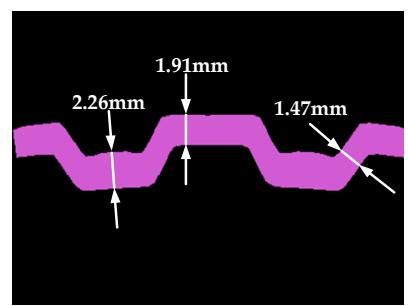

FE analysis of 2nd stage RDF process

Figure 13. Comparison of experiment and FE simulation for tooth shape.

Table 4. Comparison of the experiment and FE simulation for dimensional accuracy.

\begin{tabular}{|c|c|c|c|c|}
\hline & & $\begin{array}{l}\text { Experiment } \\
{[\mathrm{mm}]}\end{array}$ & $\begin{array}{l}\text { FE Simulation } \\
{[\mathrm{mm}]}\end{array}$ & Error $[\%]$ \\
\hline \multirow{5}{*}{$\begin{array}{l}\text { 1st stage of } \\
\text { RDF process }\end{array}$} & $\begin{array}{l}\text { Thickness of } \\
\text { inner tooth }\end{array}$ & 2.20 & 2.17 & 1.38 \\
\hline & $\begin{array}{l}\text { Thickness of } \\
\text { outer tooth }\end{array}$ & 2.20 & 2.20 & 0.00 \\
\hline & Thickness of face & 1.68 & 1.69 & 0.59 \\
\hline & $\begin{array}{l}\text { Internal } \\
\text { diameter }\end{array}$ & 154.62 & 154.46 & 0.10 \\
\hline & $\begin{array}{l}\text { External } \\
\text { diameter }\end{array}$ & 159.19 & 159.08 & 0.07 \\
\hline \multirow{5}{*}{$\begin{array}{l}\text { 2nd stage of } \\
\text { RDF process }\end{array}$} & $\begin{array}{l}\text { Thickness of } \\
\text { inner tooth }\end{array}$ & 2.29 & 2.26 & 1.32 \\
\hline & $\begin{array}{l}\text { Thickness of } \\
\text { outer tooth }\end{array}$ & 1.95 & 1.91 & 2.09 \\
\hline & Thickness of face & 1.48 & 1.47 & 0.68 \\
\hline & $\begin{array}{c}\text { Internal } \\
\text { diameter }\end{array}$ & 183.41 & 183.20 & 0.11 \\
\hline & $\begin{array}{l}\text { External } \\
\text { diameter }\end{array}$ & 187.65 & 187.44 & 0.11 \\
\hline
\end{tabular}

\section{Conclusions}

In this study, a multi-stage RDF process is designed as a manufacturing method for the drum clutch. An ANN with FE simulation is performed to determine the optimal parameters and to improve the dimensional accuracy of the drum clutch. The conclusions of this study can be summarized as follows:

(1) A multi-stage RDF process is suggested as a manufacturing method for the drum clutch to prevent decreases in the tooth strength and improve dimensional accuracy.

(2) The clearance between the roll and the mandrel is selected as the main design parameter. An ANN with FE simulation is performed to determine the optimal parameters of 
the 1st and 2nd stages of the RDF process. The process window is also constructed to obtain the relationship between the process parameters and the dimensional accuracy and could predict dimensional accuracy for all combinations within a whole range of process parameters without additional FE simulation.

(3) FE simulation considering a continuous multi-stage RDF confirms the feasibility of the suggested manufacturing process and parameters. The temperature increase and maximum stress were within the permitted safety tolerances of the actual manufacturing process. The fatigue life of tool could be improved by prevention of stress concentration during RDF process because of the rotational roll.

(4) The optimized conditions were successfully utilized to manufacture the drum clutch. The calculated dimensional accuracy of the product was in good agreement with that of the manufactured drum clutch, and the object dimensions were within an allowable tolerance. The suggested process window can be used efficiently for determination of process parameters in multi-stage RDF process to manufacture drum clutch.

Author Contributions: Methodology, D.-C.K. and Y.-H.M.; Supervision, D.-C.K.; FE simulation, J.-H.K. and J.-C.R.; Experiments, J.-H.K. and W.-S.J.; Data curation, J.-H.K., D.-C.K. and J.-H.P. All authors have read and agreed to the published version of the manuscript.

Funding: This work was supported by a 2-Year Research Grant of Pusan National University.

Data Availability Statement: The data presented in this study are available on request from the corresponding author.

Conflicts of Interest: The authors declare no conflict of interest.

\section{References}

1. Merklein, M.; Johannes, M.; Lechner, M.; Kuppert, A. A Review on Tailored Blanks-Production, Applications and Evaluation. J. Mater. Process. Technol. 2014, 214, 151-164. [CrossRef]

2. Turetta, A.; Bruschi, S.; Ghiotti, A. Investigation of 22MnB5 Formability in Hot Stamping Operations. J. Mater. Process. Technol. 2006, 177, 396-400. [CrossRef]

3. Bouzakis, K.D.; Friderikos, O.; Tsiafis, I. FEM-supported simulation of chip formation and flow in gear hobbing of spur and helical gears. CIRP J. Manuf. Sci. Technol. 2008, 1, 18-26. [CrossRef]

4. Hussain, P.B.; Cheon, J.S.; Kwak, D.Y.; Kim, S.Y.; Im, Y.T. Simulation of clutch-hub forging process using CAMPform. J. Mater. Process. Technol. 2002, 123, 120-132. [CrossRef]

5. Wu, H.C.; Altan, T. Process optimization in stamping-a case study for flanging a clutch hub from steel plate. J. Mater. Process. Technol. 2004, 146, 8-19. [CrossRef]

6. Shim, D.S.; Yang, D.Y.; Chung, S.W.; Han, M.S. Optimization of Forming Steps in the Incremental Forming of Twisted Shapes using a Line Array Roll Set (LARS). Int. J. Precis. Eng. Manuf. 2010, 11, 715-723. [CrossRef]

7. Chang, Y.C.; Hu, Z.M.; Kang, B.S.; Dean, T.A. A study of cold ironing as a post-process for net-shape manufacture. Int. J. Mach. Tools Manuf. 2002, 42, 945-952. [CrossRef]

8. Domblesky, J.P.; Feng, F. A parametric study of process parameters in external thread rolling. J. Mater. Process. Technol. 2002, 121, 341-349. [CrossRef]

9. Park, J.H.; Kim, S.G.; Kang, J.H.; Park, Y.C.; Kim, S.H.; Seo, S.R.; Park, K.H. Preform Design for Manufacturing of Automobile Drum Clutch Hub Products. J. Kor. Soc. Precis. Eng. 2008, 25, 33-38.

10. Kwon, Y.N.; Kim, S.W.; Kim, B.J.; Park, E.S.; Cha, D.J. Development of Flow Forming Process for Hollow Shaped Parts from Seamless Steel Tube. Trans. Mater. Process. 2011, 20, 611-618. [CrossRef]

11. Ko, D.H.; Lee, S.K.; Kwon, Y.N.; Kim, S.W.; Lee, H.S.; Park, E.S.; Kim, B.M.; Ko, D.C. Roll Die Forming Process for Manufacturing Clutch Hub in Automotive Transmission. Trans. Mater. Process. 2011, 22, 154-159. [CrossRef]

12. Kim, D.H.; Ko, D.C.; Lee, S.H.; Byun, H.S.; Kim, B.M. Development of Press Forming Technology for the Multistage Fine Tooth Hub Gear. J. Kor. Soc. Precis. Eng. 2008, 23, 44-51.

13. Kang, J.Y.; Kim, B.M.; Kim, Y.H.; Kim, D.H. Development of Forming Technology for Clutch Gear Using Artificial Neural Network. J. Kor. Soc. Precis. Eng. 2011, 28, 827-833.

14. Lee, K.O.; Kim, J.M.; Je, J.S.; Kang, S.S. Development of precise clutch gear for automobile transmission by compound forging process. J. Kor. Soc. Precis. Eng. 2006, 23, 185-192.

15. Ko, D.H.; Lee, S.K.; Kwon, Y.N.; Kim, S.W.; Kim, B.H.; Kim, B.M.; Ko, D.C. Improvement in Dimensional Accuracy of Roll-DieFormed Clutch Hub Used in Automotive Transmission. Int. J. Precis. Eng. Manuf. 2012, 13, 237-243. [CrossRef]

16. Kuo, Y.Y.; Yang, T.; Huang, G.W. The use of a grey-based Taguchi method for optimizing multi-response simulation problems. Eng. Optim. 2008, 40, 517-528. [CrossRef] 
17. Designation, E. 8M-04. Standard Test Methods for Tension Testing of Metallic Materials; ASTM International: West Conshohocken, PA, USA, 2016.

18. Kwak, T.S.; Kim, Y.J.; Bae, W.B. Finite element analysis on the effect of die clearance on shear planes in fine blanking. J. Mater. Process. Technol. 2002, 130, 462-468. [CrossRef]

19. Kim, D.H. An Innovative Scheme for Process Design in Metal Forming Using FEM and Intelligent Computational Optimization Ph.D. Thesis, Pusan National University, Busan, Korea, 2002; pp. 27-46.

20. Sobajic, D.J.; Pao, Y.H. Artificial Neural-Net based Dynamic Security Assessment for Electric Power Systems. IEEE Trans. Power Syst. 1989, 4, 220-228. [CrossRef]

21. Jin, G. Galling Mechanism of Cold Work Tool Steel by Frictional Heat Generation in Stamping of UHSS. Master's Thesis, Pusan National University, Busan, Korea, 2015; p. 52.

22. Pavlina, E.J.; Van Tyne, C.J. Correlation of yield strength and tensile strength with hardness for steels. J. Mater. Eng. Perform. 2008, 17, 888-893. [CrossRef] 